\title{
The Fit Between Organizational Structures and IS Implementation: The Case of IFMIS in Kenya
}

\author{
Indeje Wanyama and Qin Zheng
}

\begin{abstract}
Organizational structures are bound to influence implementation of projects. Based on concepts borrowed from Structuration Theory as advanced by sociology, this paper tries to identify organizational factors that could affect the implementation efforts of an Integrated Financial Management Information System (IFMIS). The information system in question has taken overtly a long time and it is not complete yet. We set out to find out whether organizational issues are at play in this particular project. The project under study is a large-scale integrated information system, which aims at strengthening and further developing Financial Management Information in the wider public service in Kenya. The Structuration Theory is used to help explain some of the meanings, norms and issues of power experienced during the implementation of the IFMIS. Without ruling out problems of technological nature, the findings suggest that many of the problems in the IFMIS implementation may be attributed to organizational factors, and that certain issues are related to the existing organization culture and structure within government.
\end{abstract}

Index Terms-Organizational Structure, IFMIS, Structuration Theory, Systems Implementation

\section{INTRODUCTION}

The organizational setting within which an information system is implemented forms an integral part of that

system. According to [1] ideas, practices, organizational arrangements, roles and statuses in the information system reflect the wider socio-cultural and political economic context in which they occur and are influenced by that context.

The Government of Kenya has been enhancing its financial management function since 1997. Part of this effort has been to integrate all financial related issues in one system: the Integrated Financial Management System (IFMIS). IFMIS aims at enhancing access and sharing of financial information between the Ministry of Finance and other Ministries and departments. This is an initiative that was brought on board to address the issue of discrete systems that did not "speak to each other" so to speak. While taking on this project there were systems in place that had been established and operated within given structures and an

Manuscript received on September 19, 2010. This work was supported in part by the Chinese Scholarship Council and The Ministry of Finance-Kenya

Indeje. W is with the Ministry of Finance-Kenya and a PhD student at the Shanghai University of Finance and Economics (corresponding author, phone+254722848087, email_windeje@yahoo.com)

Qin Z. is with the Shanghai University of Finance and Economics School of Information Management and Engineering, 200433, Guoding Road 777-Shanghai, PRC cell: +8613391211216, fax: +862165904540 , email: qinzheng@mail.shufe.edu.cn established organization culture. Working practices that surround the collection, storage, analysis and transmission of routine financial data throughout the administrative hierarchy, are often in tension with situational, individual and organizational factors of work, which together make up an organization culture.

Organizational culture can support linkages between technology adoption and organizational growth [2], and can thus be a critical success factor in the development and implementation of information systems. Consequently, there is a need for understanding how a particular organization culture facilitates or limits implementation process of an information system. As part of an ongoing research, we, in this paper, discuss the implementation of the IFMIS project following an action research approach. The action research approach being used is characterized by the adaptation, localization and implementation of the system, and training of the users on its use. The research reported herein employs an ethnographic research approach, which reflects our aim of understanding the phenomenon of IFMIS implementation within the organizational, national and cultural contexts where it occurs.

In section 2 the theoretical framework of the study is presented highlighting information systems and cultural aspects focusing on Structuration Theory, and the social and cultural aspects of the case under study. We describe the research approach and research methods in section 3. Section 4 , presents the case study and the IFMIS efforts underway in Kenya. Section 5 provides a discussion of preliminary findings from the research and analysis of the case study making use of concepts from Structuration Theory relevant to organization culture and IS development. In section 6, we draw our conclusions based on which we make some recommendations.

\section{STRUCTURATION THEORY}

Structuration theory was advanced by [3], [4] and is based on the premise that the classic actor/structure dualism has to be reconceptualized as a duality -- the duality of structure [3], [4]. The structural properties of social systems exist only in so far as forms of social conduct are reproduced chronically across time and space. Behavior and structure are intertwined; people go through a socialization process and become dependent of the existing social structures, but at the same time social structures are being altered by their activities. Put in different words, this means that social structures are the medium of human activities as well as the result of those activities. Social structures not only restrict behavior but also 
create possibilities for human behavior.

The point is, it is not all about the restrictions people encounter in unrolling their behavior in space and time, but people also contribute to the creation of a certain time-space-structure. The structuration of institutions can be understood in terms of how it comes about that social activities become 'stretched' across wide spans of time-space. According to [3], [4] this theory draws together the two principal strands of social thinking. Structuration theory attempts to recast structure and agency as a mutually dependent duality [5]. Reference [4] describes structuration as a social process that involves mutual interaction of human actors and structural features of the organization.

When people act in organizations, they recursively create dimensions of social interaction. In this discussion, we are particularly concerned with meaning, norms and power (following [3]. Actors draw upon interpretive schemes that mediate communication, resulting in the dialectical production and reproduction of structures of signification which constitute meanings. Interpretive schemes represent the organizational rules that inform and define interaction and are also reinforced or changed through social interaction [6]. While norms consist of rights and duties expected of actors in interaction, actors draw upon structures of domination and sanctions when exercising power. The use of power in organizations is also mediated through the organizational resources that participants bring to and mobilize within interaction [3].

Human action is defined by the ability to perform an action rather than by its intentions, as human actions have both intentional and unintended consequences [4]. The effects of intentional acts always go beyond any individual's intention and/or control, over time and in society, coming from before and extending beyond particular instances, through but beyond the specific interactions between individuals and through collective or collaborative activity. This is a theory that gained influence in sociology and the social sciences generally during the past two decades.

\section{A. Application in Information Technology field}

Structuration theory is a general theory of the social sciences; in its original formulation, ST pays little attention to technology [7]. However, given the pervasiveness of technology in organizations' everyday operations, and especially the role of information technology in the process of enactment and reality construction in contemporary organizations, some attempts have been made to extend [3], [4] ideas by including an explicit IT dimension in social analysis [8], [9] As a result of such attempts, structurationist analyses have helped to increase our understanding of important IT-based contemporary phenomena. Some recent examples are studies on electronic trading and work transformation in the London insurance market [10]; globalization issues and IT deployment in India and Britain [11]; [12]; the dynamics of groupware application [13]; communication and collaboration using IT [14]; global virtual team dynamics and effectiveness [15]; and crosscultural software production and use [9].

Other significant efforts have been indicated of the application of this theory in the IS and Information
Technology (IT) field as well; see for example, [6] on analyzing IT as a form of structuration, [16] on studying technologies in organizations, [17] in analyzing Computer-Supported Cooperative Work (CSCW) applications as structures, [8] on interpreting information systems in organizations, and [18] in their discussion of social theory for understanding the use of IT. The focus in this paper is on how Structuration Theory may offer a way of looking at the role and influence of organization culture in information systems development and implementation. The selection of Structuration Theory is based on the fact that Structuration Theory provides an understanding of human work as social interaction within a culture, mediated by artifacts such as tools, language, rules and procedures, and open to change. Thus Structuration Theory offers a broad understanding of the organizational culture in which the IFMIS development and implementation process is taking place.

The theory of structuration recognizes that human actions are enabled and constrained by social structures, which are the result of previous human actions, which [4] describes as the duality of structure. 'Structures' consist of norms, rules and resources that human actors recursively employ in their everyday interactions. These rules and resources mediate human action and at the same time delimit the same action. Consequently, the key conceptual approach of Structuration Theory provides the link between human actions in the FIS, in this case, the actions of officers involved in financial management, and the social structures, the public financial management organizational structure within which the FIS is situated. People act within structures that they change through their actions, which gives them the ability to change their environment [18]

\section{B. Financial information systems as organizations}

We can view a financial information system as a combination of people, material resources (equipment, hardware and software, supplies), and procedures organized to provide financial information to financial managers for decision making purposes. At a minimum, an information system must have the following technical elements: input (data), processing, in which input data are transformed into outputs, and an output (information). It also includes a storage element, where data can be stored before and after processing [19] However, information systems cannot be understood independently of the people around them; their social relationships, their culture and the work practices that they are engaged in within everyday life. In order to gain a better understanding of information systems development, implementation and use, research and development regarding a particular information system must involve a better understanding of how people work and the social practices and organization culture in which they are engaged.

An information system includes the social system, which in turn, has its own subsystems of people, business processes, social structure, and culture. The problems of development, implementation and use of information systems are well known and invariably they concern interactions between human, organizational and technical factors, which cannot be separated. Therefore, information systems should not be 
regarded as technical systems with behavioral implications but are better conceptualized as social systems in which technology is only one of the elements [21]. The study reported here explores organizational factors and their impact in information systems development and implementation.

An Integrated Financial Management Information System (IFMIS) will generally consist of several distinct components or modules that use information to perform different functions. Figure 1 presents a basic diagram of a typical government IFMIS, including several core components, as well as non-core components that will either be integrated into the system or connected to the system via an interface. Bear in mind that some systems are far simpler, while many are far more complex in scope and functionality.

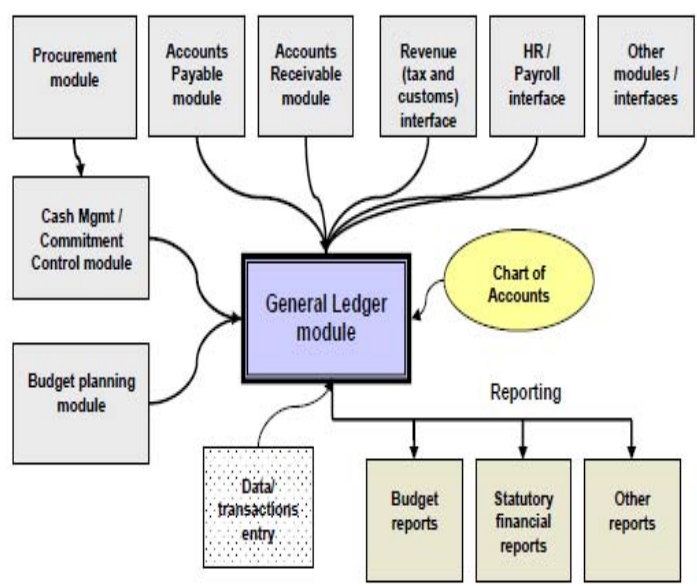

Figure 2: Components of a typical IFMIS (adopted from [21].

At the core of the system is the General Ledger. The General Ledger constitutes the central "books" of any IFMIS. Every transaction entered into the system posts to the General Ledger, starting with the allocation of budget funds through to the commitments to payment for goods and services. All transactions should simultaneously post to the General Ledger and to all appropriate sub-ledgers/modules following the rules imposed by a standardized chart of accounts. These records remain as a permanent track of the history of all financial transactions, and represent the source from which all reports and financial statements are derived.

\section{INFORMATION SYSTEMS AND CULTURE}

Reeves and Baden define culture as comprising "the distinctive patterns of ideas, beliefs, and norms which characterize the way of life and relations of a society or group within a society" [22]. Keesing argues that culture refers to "humans' knowledge, not what they do and make. It is this knowledge, which provides standards for deciding: what is..., what can be..., how one feels about it..., what to do about it..." (Keesing, 1981: 68-69 cited by [1]: 3). Generally therefore, culture can be considered as a set of ideas, and rules; that is, culture comprises systems of shared ideas, systems of concepts and rules and meanings that are expressed in the ways that humans live.

Although they find it difficult to define [23]; [24], view organizational culture as a set of commonly shared beliefs, knowledge, attitudes, and customs held by a particular group [25]. Another popular and somewhat more straightforward definition of organizational culture is simply "the way things get done around here" [26].

On the other hand, organizational culture governs the conduct of people and how the organization operates interms of language and communication, work efficiency, meaning of authority, hierarchy and managerial power, strategic change, and creation and utilization of knowledge. Organizational culture has also been shown to play a significant role in information technology management processes [27] and the management of new IS development projects [28].

At the center of organizational culture are assumptions about human nature (e.g. as dishonest or trustworthy), which frequently operate unconsciously and ultimately determine how different organization members perceive their work, treat their customers, and relate to one another [29]. As a system of values, beliefs, and assumptions, culture has a powerful influence on employee work-related attitudes such as job satisfaction, commitment to the organization ([29] and their ability or willingness to adapt and perform well [25].

\section{A. Information systems as social systems}

The problems of information systems development, implementation and use are considered to be more severe in developing countries in terms of factors such as the current state of skills and knowledge, availability of suitable tools and infrastructure, lack of financial resources, shortage of technically competent personnel and constraints imposed by the social and political context [19]. Financial information systems like other information systems are not only complex but are also social systems since they are deeply embedded in social working practices. For example [30] while focusing on health information systems, argue that "the success of health information systems reform depends not only on technical improvements but also on in-depth understanding of political, socio-cultural, and administrative factors". This is a common tenet across information.

The existing work practices and organization culture re-enforce existing social relationships between clerical officers at grassroots levels and their managers at higher levels. For example, clerical officers at grassroots levels view the data they are collecting as means for showing their managers what they do rather than seeing financial management information as a means for planning and allocation of resources and decision making for prudent financial management.

\section{B. Organization culture and information infrastructure}

Introduction of a new information system fundamentally changes the way operations are carried out and therefore requires a carefully managed process. This process results in the creation of a new organizational culture that is, changing the way the organization operates. As [30] puts it:

Even if a perfectly relevant, well-organized, and technologically sound routine information system were readily available, it would not be possible to introduce it immediately. The main issue is that information systems are managed and used by people who have certain beliefs, attitudes, and practices, and changing them will take time [30]: 24). 
As already highlighted above, an organization's culture refers to the shared beliefs, values and perceptions of organization members about a system's practices and procedures [31]. Organization culture governs the conduct of people and how the organization operates, for example, in terms of language of communication, work efficiency, meaning of authority, hierarchy and managerial power, strategic change, creation and utilisation of knowledge. Organizational culture has been found to play a significant role in information technology management processes such as technology-driven change [27] groupware development and deployment [32] and management of new systems development [28].

Organizations adapt to their external environments by developing responsive structures and systems, adopting relevant technologies, and harvesting appropriate skills and qualities. Though constrained by its environment, an organization makes a number of choices which collectively define its culture over time. These choices are influenced by the philosophy of the organization and ultimately the choices will also define the success or failure of information systems development and implementation in a particular organization [33].

According to [34] organizational culture can be viewed as an information infrastructure. An information structure that has key characteristics that can be described as shared - a foundation underlying and supporting other activities in a community; evolving - its use areas growing, i.e., more components are added and more users are adapting to and changing the organization culture; open - without borders regarding the number of actors that may be included; standardized - having a minimum set of functionalities that allows different solutions to work at different levels; heterogeneous - including components of different kinds, i.e. technological and non-technological; and having an installed base - each new version of a component replacing an existing one has to fit with the infrastructure as it is at that moment For an organization to continue to innovate its activities there is a need to consider the already existing organization culture during the innovation process. In other words, we conceptualize organization culture as constitutive of the installed base of an information infrastructure.

\section{Methodology}

The study took up the key concepts of meaning, norms and power from Structuration Theory (following [8] to inform the research design, the iterative process of carrying out the fieldwork, and subsequent analysis. In doing so, we were persuaded by the fact that without considering the organizational context within which the Integrated Financial Management Information Systems (IFMIS) is being implemented, it's not easy to understand the intrigues faced by the project. In order to identify the organizational factors that have affected the implementation of IFMIS in Kenya, we chose an ethnographic research approach, with semi-structured interviews, participant observation and review of documents as the main research methods. This paper is a piece of ongoing research that began 2009, by defining a plan for field research, identifying documentary sources and conducting analysis of existing IS, followed by gaining permission from the Ministry of Finance for access to project documentation and contact interviews to and observation of personnel that are involved in the implementation of IFMIS either as users, technical support staff or senior management. The interviews took place in the respective officers' offices lasting approximately one hour. The time spent in each interview included the introduction of the purpose of the interview along with the reassurance of confidentiality of the interviewees' responses.

The use of these different data collection methods where information is gathered from a variety of sources that are pitied against each other in order to cross-check data and interpretations is very important. [35] suggests that different methodologies like questionnaires, interviews, and document studies, should be used where possible for this very reason. [35] refers to this validity check as triangulation. On the other hand, [36] refers to the same concept as "convergent validity" the degree to which attempts to capture the same concept with different methods converge.

\section{Financial Management: Kenyan ScEnario}

After the preparation and presentation of the national budget to the National Assembly (Parliament) by the Minister of Finance, the Ministry issues guidelines to the line ministries on the implementation and execution of the budget. These guidelines are in addition to existing regulations and circulars issued by the Ministry from time to time. Based on these guidelines, Line Ministries manage the finances under their care and report to Treasury. In managing the finances, ministries and departments have traditionally used stand alone systems that were provided by the Treasury. However these were evaluated as fragmented and uncoordinated with little capacity for data-handling and little active use of financial data at different levels of the national financial system. The information flow was bottom-up driven with no significant feedback between the higher and lower levels and between different departments.

This resulted in line ministry officers being heavily overburdened by many data-handling tasks for multiple vertical systems, with different departments at Treasury seeking similar information from line ministries and departments. In addition, the fact that these systems could not share information meant that the same information had to be entered over and again in different systems. Generally, these problems dictated that the existing systems were ineffective, unreliable and fragmented.

\section{A. IFMIS initiative in Kenya}

Since 1997, the Government of Kenya has been implementing wide ranging public financial management reforms aimed at improving financial management, accountability, and transparency of public funds, [37]. During the first two phases over the first three years, a number of diagnostic reviews were conducted and a Financial Management Information Systems Strategy developed, [38a], [39].

Following a procurement delay of almost two years, a contract for the purchase of the software implementation was 
finally awarded in late 2002, the hardware procurement having been undertaken separately from the software. The project was to be implemented in phases, with the initial phase targeting the procurement and the accounting modules at the Treasury and two line ministries during the financial year 2003/2004,[38b] The roll-out of these two modules has since been done for all ministries and departments across government. However the budgeting, asset management, debt management, external resource and the human resource management modules are yet to be implemented. The IFMIS sought to introduce computers and train financial management staff at all levels of government to aid the data-handling processes and active use of information. However, bringing about this change in practice has proved to be an extremely complex and long-term task. One of the reasons for this is the nature of existing work practices and organizational culture that is evident in many an organization, which we argue need to be understood when developing and implementing initiatives such as the IFMIS.

\section{ANALYSIS AND DISCUSSION}

\section{A. Organizational Culture Challenges}

Previously, training on financial management systems had never involved senior financial management officers as trainees since many of them are always busy with other managerial activities that include attending meetings. In addition, the functional aspects of earlier systems did not require that the senior managers get training on them. However the introduction of IFMIS dictated that these senior officers had to attend the training, a requirement that proved to be an uphill task. At the very best these senior managers send their officers for the training. In some unfortunate cases those send for the training were considered dispensable by their bosses who could not afford to have their more reliable staff away from the office on training. This perception manifested itself in the eventual adoption and acceptance of the system. Many departments still made use of the old stand-alone systems even after the introduction of IFMIS.

Similarly, the officers who were trained on IFMIS and are responsible for collating data and generating reports ended up at best as data entry clerks since the reports from the system were generic and not easy to understand let alone to generate. Given the feasibility of the earlier systems, many users relied on reports generated by these systems and only produced reports using IFMIS mainly to comply with the Ministry of Finance directive. At the time of data collection, ministries and departments were in the process of preparing final accounts for the financial year 2008/2009. The first author experienced firsthand ministries preparing two sets of reports, one prepared using the previous system and the other prepared using IFMIS. Asked why they were doing so, the officers responded that they can only append a signature on what they own. And what they own according to them were the reports prepared by the previous system.

The implementation and administration of the IFMIS is centered at the Ministry of Finance under the Accountant Generals department, where we have the system technical support staff. Other ministries and departments are dependent on these personnel both for system troubleshooting and maintenance, including approvals to access the system. Whereas these controls are crucial to ensure the security and integrity of the system, they have come with other impediments to the smooth flow of work. For example when a line ministry or department experiences a technical hitch, they have to seek assistance from the Accountant Generals office. The response time is not always as soon as expected and this does literally stop the flow of work that is dependent on IFMIS.

Though not explicitly expressed, the centralization of the IFMIS project under the Accountant Generals office may have had the effect of causing resentment among other departments that claim a stake in the IFMIS. These departments include the Budgetary Supply Directorate, Human Resource Directorate, Debt Management, External Resources Department and Procurement Directorate among others. The fact that long after IFMIS was initiated, the Human Resource Directorate developed a Human Resource Management system "the Integrated Personnel Payroll Database (IPPD)" could be just one of the indications of this resentment. Given that human resource management is one of the modules in IFMIS, there was no rational to develop a somewhat parallel system. Efforts to have the IPPD data integrated in the IFMIS have not been successful. The frustrations arising from this case were best captured by the June 2006 issue of the consultants' project quarterly report:

"Despite many attempts, it has proven very difficult to convene meetings with the developers of the Integrated Personnel \& Payroll Database (IPPD). Also the standalone nature of the IPPD, (where each ministry operates its system on a standalone PC rather than on a centralized server) creates problems for developing a truly effective interface" [40]

The interviews captured the perceived resistance amongst different groups involved with the project either as users or developers including project administration and support staff. It emerged from these interviews that there are groups of participants who indeed believe the project has a business case and should have been completed on schedule to reap the benefits there off, similarly, there are those who believe the project was ill conceived and more consultation needed to have been done before implementing the project.

The participants interviewed clearly believed that the proposed centralization of the financial information resources was what led to the resistance to the change, and this was equally true of those interviewees who supported centralization, and those against it. The findings from the interviews and conversation with the participants especially the project administrative and support staff demonstrated that there was a great deal of emotional reaction to the direction the project has taken, there was sometimes more furor than reason in these conversations. Some interviewees seemed pleased that the project has not come to its successful completion, although their reasons differed. These reasons included, the belief that the project should have never been started because integrating financial functions across the government would never work; the project management style was inappropriate, particularly when it came to dealing with the users; and that there was a lack of any real common 
understanding between users and the development team about the purpose of the project. A consensus seems to be the fact that, a perceived threat to organizational areas of control turned initial support for the project into fatigue and therefore the need not to see the project succeed

\section{EMERGEnCE Of The Structuration TheOry CONCEPTS}

As discussed earlier, the theory of structuration holds that all human action is performed within the context of a pre-existing social structure which is governed by a set of norms and/or laws which are distinct from those of other social structures. Therefore, all human action is at least partly predetermined based on the varying contextual rules under which it occurs. However, the structure and rules are not permanent and external, but sustained and modified by human action overtime.

Domination as one of the types of the structures in social systems is evident in the implementation of this project. Acts of power play are visible in the utilization of the system. The system users at the line ministries and departments' level have limited power as compared to the system administrators at the Ministry OF FinANCE. ON THE OTHER HAND THE ACCOUNTANT GENERALS DEPARTMENT HAS LIMITED POWER TO INFLUENCE OTHER DEPARTMENTS THAT HAVE A STAKE IN THE IFMIS PROJECT. THESE ACTIONS ARE INFLUENCED BY NORMS, RULES AND POSSIBLE SANCTIONS. BY FOLLOWING set out norms, some officers have had an impact on their fellow officers' structure of work.

\section{CONCLUSION}

These findings indicate that organization culture has a strong influence on financial information systems development and implementation. The identification and understanding of meanings, norms and power in organizations is an important consideration when developing and implementing an information system. The study reveals how the IFMIS implementation activities in Kenya are caught in conflict with time, norms and rules that are pertinent to organizations. The issues of power are expressed within the public service daily activities, that is, between not only different levels of officers but also within the same level and between the lower levels and higher levels of government.

\section{ACKNOWLEDGEMENT}

Indeje. W would like to appreciate the financial support from both the Chinese Scholarship Council and the Budgetary Supply Department, Ministry of Finance Kenya.

\section{REFERENCES}

[1] Hardon, A., Boonmongkon, P., Streefland, P., Tan, M., Hongvivatana, T., Geest, S.V.D., Staa. A.V., Varkevisser, C., Chowdhury, M., Bhuiya, A., Sringeryuang, L., Dongen, E.V. and Gerrits, T. (2001). Applied Health Research Manual: Anthropology of Health and Care. The Netherlands: Het Spinhuis Publishers.

[2] Chatman, J. A. and Jehn, K. A. (1994). Assessing the relationship between industry characteristics and organizational culture: how different can you be?, Academy of Management Journal, vol. 37, no. 3, 522-554.

[3] Giddens, A. (1979). Central Problems in Social Theory: Action, structure and contradiction in social analysis. University of California Press.

[4] Giddens, A. (1984). The Constitution of Society: Outline of the Theory of Structuration, Cambridge: Polity Press.

[5] Rose, J. (1999). Towards a structurational theory of IS, theory development and case study illustrations. In: Pries-Heje et al. (Eds.) Proceedings of the 7th European Conference on Information Systems. Copenhagen: Copenhagen Business School.

[6] Orlikowski, W. J. (1992). The duality of technology: Rethinking the concept of technology in organizations, Organization Science, vol. 3, no. $3,398-427$.

[7] Jones, M. (1997) 'Structuration theory and IT,' in Re-thinking Management Information Systems. Currie and Galliers (eds.), 103-135. Oxford

[8] Walsham, G. (1993). Interpreting Information Systems in Organizations. Chichester: Wiley.

[9] Walsham, G. (2002). Cross-cultural software production and use: a structurational analysis. MIS Quarterly 26 (4): 359-380.

[10] Barrett, M. and Walsham, G. (1999) Electronic trading and work transformation in the London Insurance Market. Information Systems Research 10 (1): 1-21.

[11] Nicholson, B. and Sahay, S. (2001). Some political and cultural issues in the globalization of software development: case experience from Britain and India. Information and Organization 11: 25-43.

[12] Walsham, G., and Sahay, S. (1999). GIS for District-level Administration in India: Problems and Opportunities, MIS Quarterly, 23 (1), 39-65.

[13] Ngwenyama, O. (1998). Groupware, social action and organizational emergence: on the process dynamics of computer mediated distributed work. Accounting, Management and Information Technology: 127-146.

[14] Olesen, K. and Myers, M.D. (1999). Trying to improve communication and collaboration with information technology - an action research project which failed. Information Technology \& People 12 (4): 317-332.

[15] Maznevski, M. and Chudoba, K.M. (2000) Bridging space over time: global virtual team dynamics and effectiveness. Organization Science 11 (5): 473-492.

[16] Orlikowski, W.J. (2000). Using technology and constituting structures: A practice lens for studying technology in organizations. Organization Science, 11(4), 404-428.

[17] Lyytinen, K. and Ngwenyama, O. K. (1992). What does computer support for cooperative work mean? A structurational analysis of computer supported cooperative work, Accounting, Management and Information Technology, vol. 2, no. 1, 19-37.

[18] Bratteteig, T. and Gregory, J. (1999). Human action in context: A discussion of theories for understanding use of IT. In: T. Käkölä (ed.), Proceedings of the 22nd Information Systems Research Seminar in Scandinavia (IRIS 22): Enterprise Architectures for Virtual Organisations. Jyväskylä, FI: U. of Jyväskylä, Computer Science and Information Systems Reports, Technical Report TR-21, 1999.

[19] Ties, J. B. (1991). Health Information for Primary Health Care, African Medical and Research Foundation, 1-179.

[20] Walsham, G., Symons, V. and Waema, T. (1988). Information Systems as Social Systems: Implications for Developing Countries, Information Technology for Development, vol. 3, no. 3, 189-204.

[21] 21. Gallagher, M and Rozner. S (2008). "Integrated Financial Management Information Systems: A Practical Guide," funded by USAID under Contract GEG-I-06-04-00001-00 Task Order No. 06.

[22] Reeves, H. and Baden, S. (2000). Gender and Development: Concepts and Definitions. Brighton, UK: Institute of Development Studies, University of Sussex, Report No. 5.

[23] Hofstede, G., Neuijen, B., Ohayv, D. \& Sanders, G. (1990). Measuring organizational cultures: A qualitative and quantitative study across twenty cases. Administrative Science Quarterly, 35, 285-316.

[24] Lee, C. \& Chen, W.J. (2005). Management in the information technology industry. International Journal of Management, 22(4), 661.

[25] Bassi, L. (1997). Harnessing the power of intellectual capital. In J. Cortada \& J. Woods (Eds.), The Knowledge Management Yearbook 1999-2000. Butterworth-Heinemann.

[26] Deal, T. \& Kennedy, A. (1982). Corporate cultures. Reading, MA: Addison-Wesley.

[27] Cabrera, A., Cabrera, E. F. and Barajas, S. (2001). The key role of organizational culture in a multisystem view of technology-driven 
change, International Journal of Information Management, vol. 21, no. $3,245$.

[28] Newman, M., and Sabherwal, R. (1996). Determinants of Commitment to Information Systems Development: A Longitudinal Investigation, MIS Quarterly, vol. 20, no. 1, 43-47.

[29] Sikorska-Simmons, E. (2006). Organizational culture and work-related attitudes among staff in assisted living. Journal of Gerontological Nursing, 32(2), 19-27.

[30] Lippeveld, T. (2001). Routine Health Information Systems: The Glue of a Unified Health System. In: The RHINO workshop on issues and innovation in routine health information in developing countries. The Bolger Center, Protomac, MD, USA 14-16 March 2001. Arlington, VA USA: MEASURE Evaluation, JSI Research and Training Institute, 13-27.

[31] Schneider, B. (1975). Organizational climates: An essay, Personnel Psychology, vol. 28, 447-479

[32] King, W. R. (1996). Strategic issues in groupware, Information Systems Management, vol. 13, no. 2, 73-75.

[33] Balthazard, A. P. and Cooke, A. R. (2004). Organizational Culture and Knowledge Management Success: Assessing the Behavior-Performance Continuum. In: Proceedings of the 37th Hawaii International Conference on Systems Sciences, 2004.
[34] Hanseth and Monteiro, (1997) Inscribing behaviour in information infrastructure standards. Accounting, Management \& Information Technology. v7 i4. 183-211.

[35] Guba E. G (1981) "Criteria for assessing the trustworthiness of naturalistic inquiries” ERIC/ECTJ Annual Review Paper, 29, 2, 75-91

[36] Jordan, E (1994) "Improving the Quality of IS Research: Key Issues for Debate", In Proceedings of the IFIP TC8 Open Conference on Business Process Re-Engineering: Information System Opportunities and Challenges, ACS, Qld, Gold Coast, May 8-11, 1994

[37] Government of Kenya (1997) Strengthening Government Finance and Accounting Functions. Consultant Report prepared by KPMG Nairobi

[38] 38a Government of Kenya (1999) Financial Management Information Systems Strategy Consultant Report prepared by International Management Consultants Limited COLCHESTER UK

[39] 38bGovernment of Kenya (1999) Strengthening Government Finance and Accounting Functions. Implementation Plan. Consultant Report prepared by International Management Consultants Limited COLCHESTER UK

[40] Government of Kenya (2000) Strengthening Government Finance and Accounting Functions. Comprehensive Project Memorandum

[41] Government of Kenya (2006) Strengthening Government Finance and Accounting Functions. Project Quarterly Progress Report. 